name. We can not introduce a new name in most cases despite our most serious efforts. For over a century a little gray neighbor of man had borne the dignified name of body louse, then the war threw us into the trenches and zowie! We came out with cooties! It is unfortunate that the economic entomologists did not have foresight enough to introduce all of our unnamed pests into "the big parade" so that each would have come out wearing an A. E. F. name as firmly fixed for distinguished service as cootie.

\title{
GEOTRUPES HORNI BLANCHARD
}

This is one of the common species of the genus in this locality occurring, according to my series, from August 8 to September 30. It can be easily distinguished from the other species by its pure black color with no metallic reflections. I have found it frequently under a fungus having an acrid milky juice (Lactarius, perhaps piperatus) and it often bores from the top down through the stem and into the ground to a depth of five or six inches; I have never noticed this particular mode of attack by $G$. balyi Jek. which at times frequents the same species of fungus. I have found an adult, a pupa and a larva beneath the same fungus though it is not certain they were all horni. Generally but one or two specimens are taken under one plant while balyi may occur in from two to six specimens. Horni occurs in rather dense growths of oak and I took several specimens in a pine grove at South Paris, Me., on September 20, 1928. It was taken at Monmouth, Me., on September 4 and 9, 1917, under fungi. A dead specimen was picked up on the sand area back of the beach at Surfside on Nantucket Island on September 13, 1928. The range of this species is much greater than formerly recorded as I have a specimen taken by Dr. T. H. Frison at Urbana, Illinois, bearing the unusual date of April 16, (1914).

C. A. Frost. 

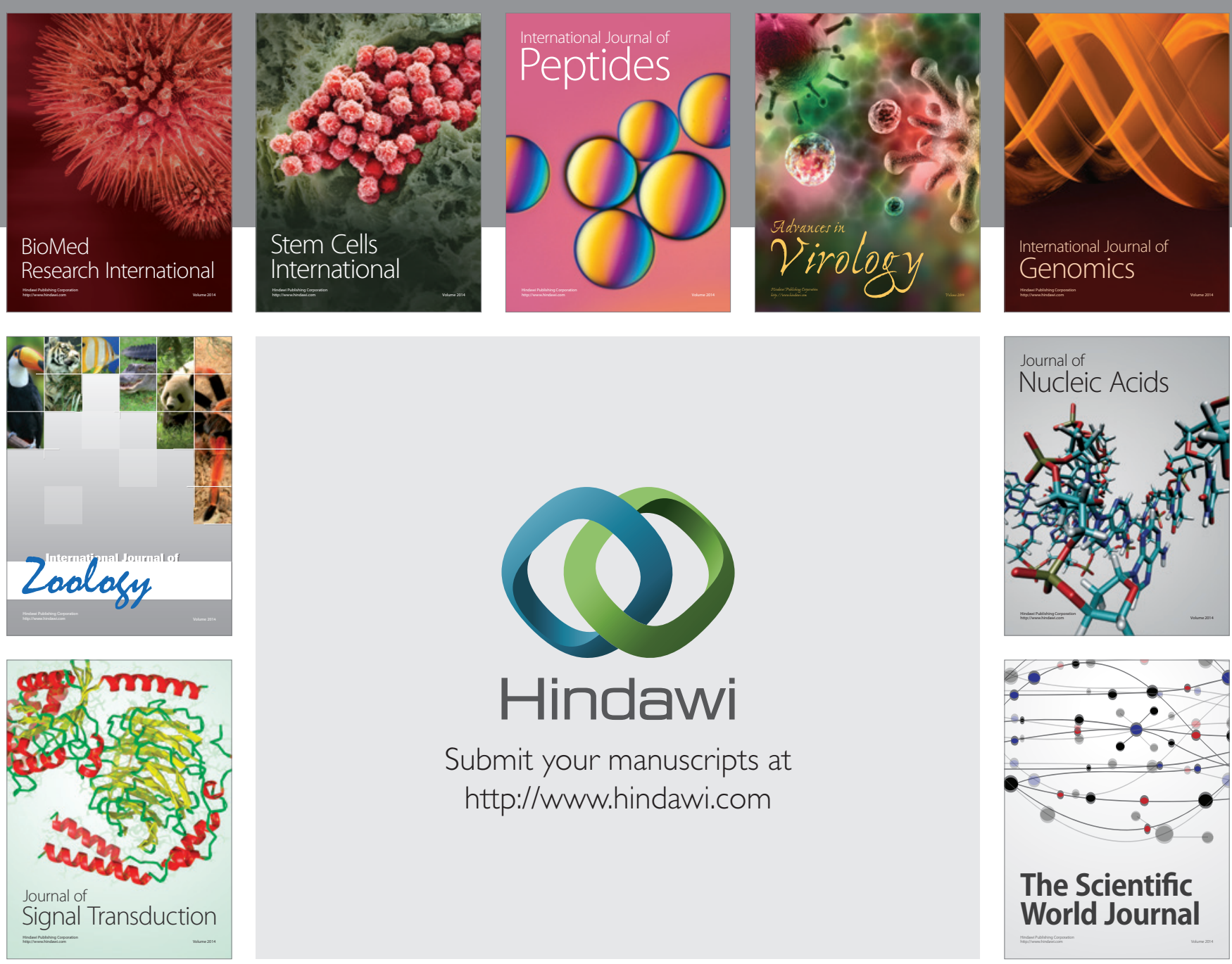

Submit your manuscripts at

http://www.hindawi.com
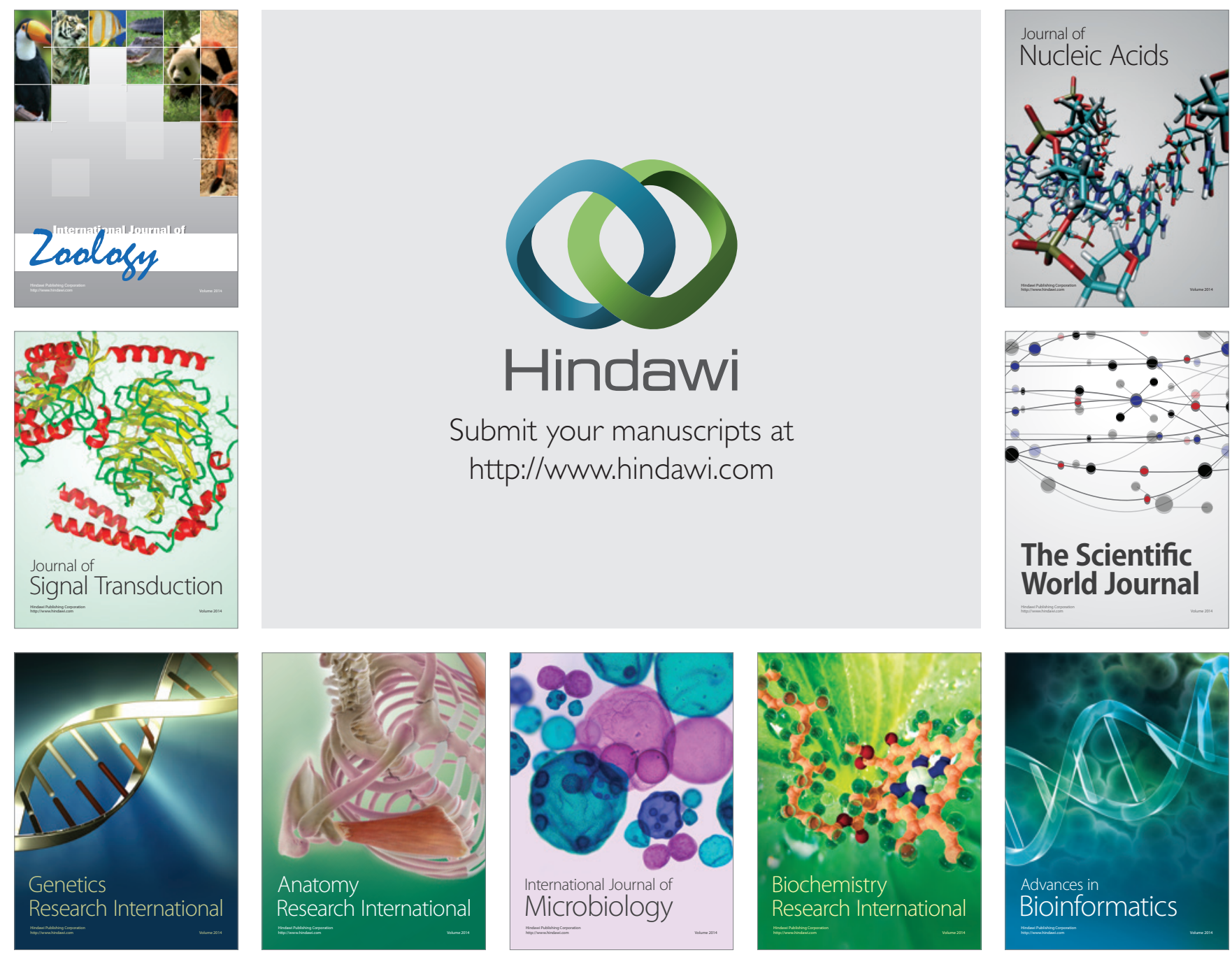

The Scientific World Journal
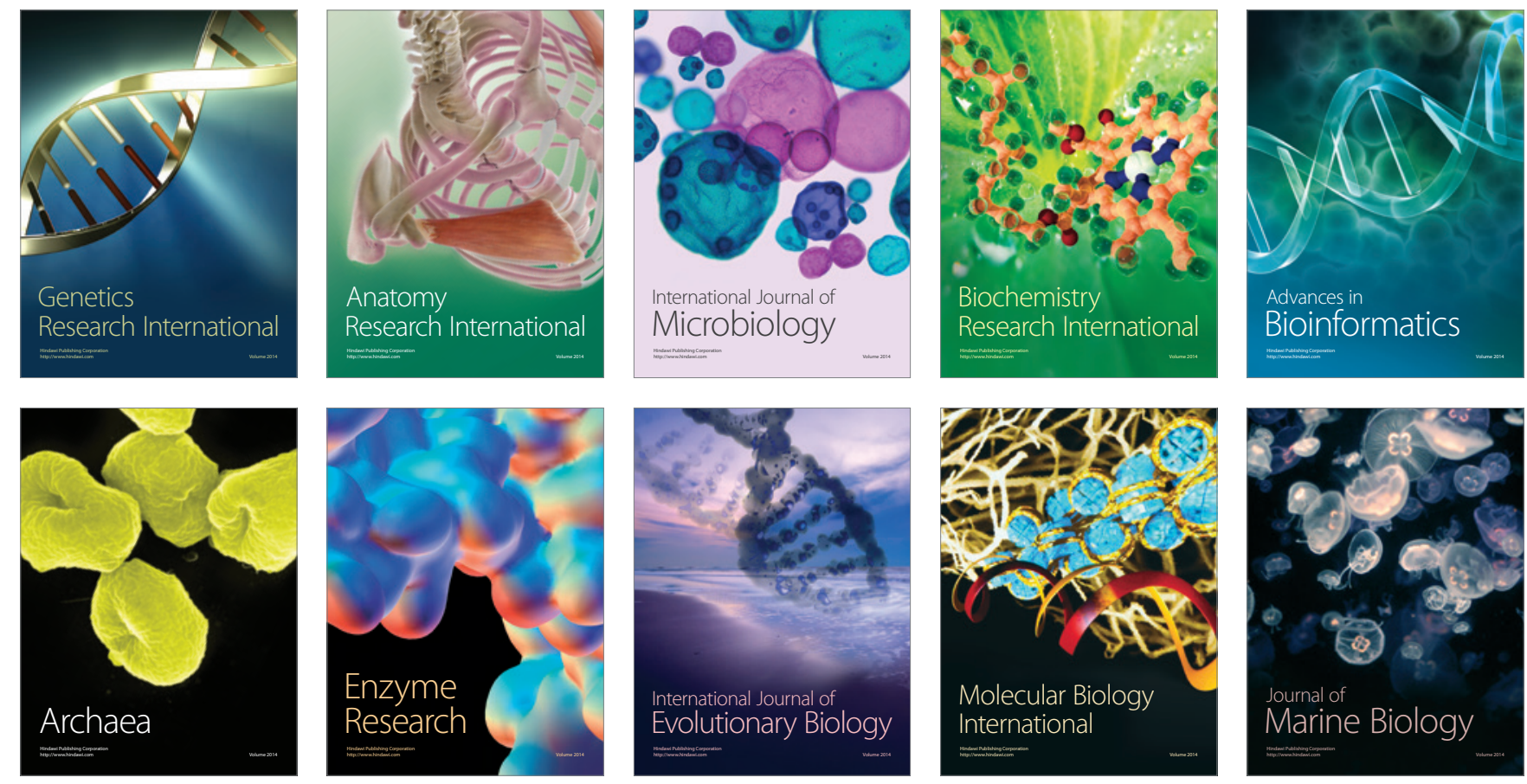